\title{
Corrigendum to "Effects of rhBMP-2 Loaded Titanium Reinforced Collagen Membranes on Horizontal Bone Augmentation in Dogs"
}

\author{
Ki-Sun Lee $\mathbb{D}^{1},{ }^{1}$ Yu-Sung Jeon, ${ }^{2}$ Sang-Wan Shin, ${ }^{1}$ and Jeong-Yol Lee $\mathbb{D}^{1}$ \\ ${ }^{1}$ Department of Prosthodontics, Korea University Guro Hospital, Seoul, Republic of Korea \\ ${ }^{2}$ Graduate School of Clinical Dentistry, Korea University, Seoul, Republic of Korea \\ Correspondence should be addressed to Jeong-Yol Lee; wddc@korea.ac.kr \\ Received 17 February 2018; Accepted 28 February 2018; Published 20 March 2018 \\ Copyright (c) $2018 \mathrm{Ki}$-Sun Lee et al. This is an open access article distributed under the Creative Commons Attribution License, \\ which permits unrestricted use, distribution, and reproduction in any medium, provided the original work is properly cited.
}

In the article titled "Effects of rhBMP-2 Loaded Titanium Reinforced Collagen Membranes on Horizontal Bone Augmentation in Dogs" [1], the Authors' Contributions section was missing and should be added as follows:

\section{Authors' Contributions}

Ki-Sun Lee and Yu-Sung Jeon contributed equally to this work.

\section{References}

[1] K. Lee, Y. Jeon, S. Shin, and J. Lee, "Effects of rhBMP-2 loaded titanium reinforced collagen membranes on horizontal bone augmentation in dogs," BioMed Research International, vol. 2017, Article ID 7141296, 8 pages, 2017. 


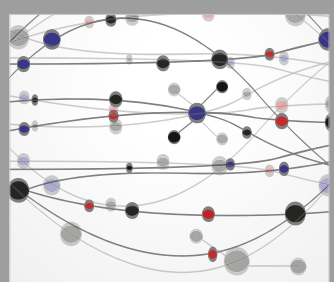

The Scientific World Journal
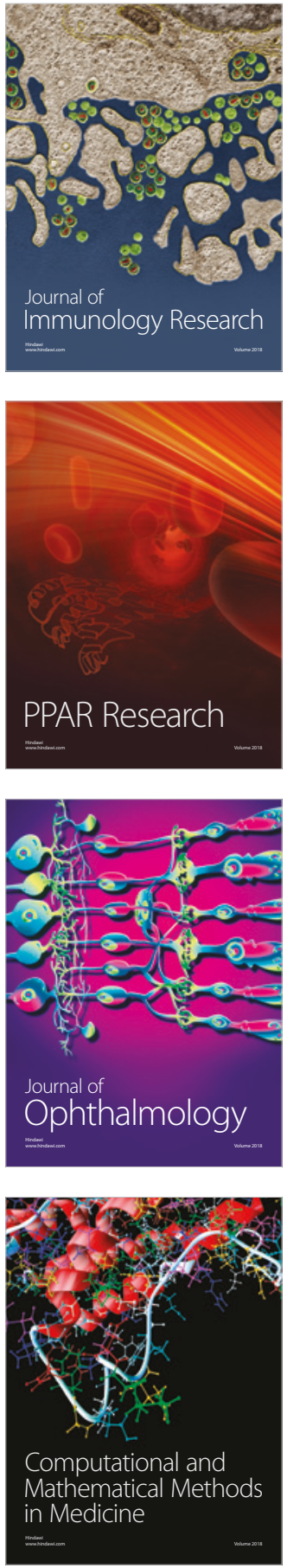

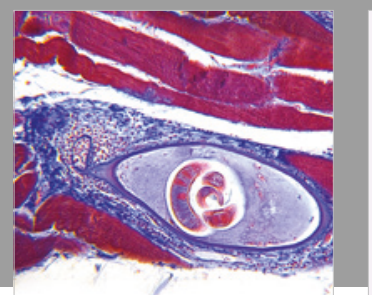

Gastroenterology Research and Practice

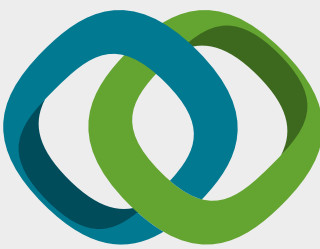

\section{Hindawi}

Submit your manuscripts at

www.hindawi.com
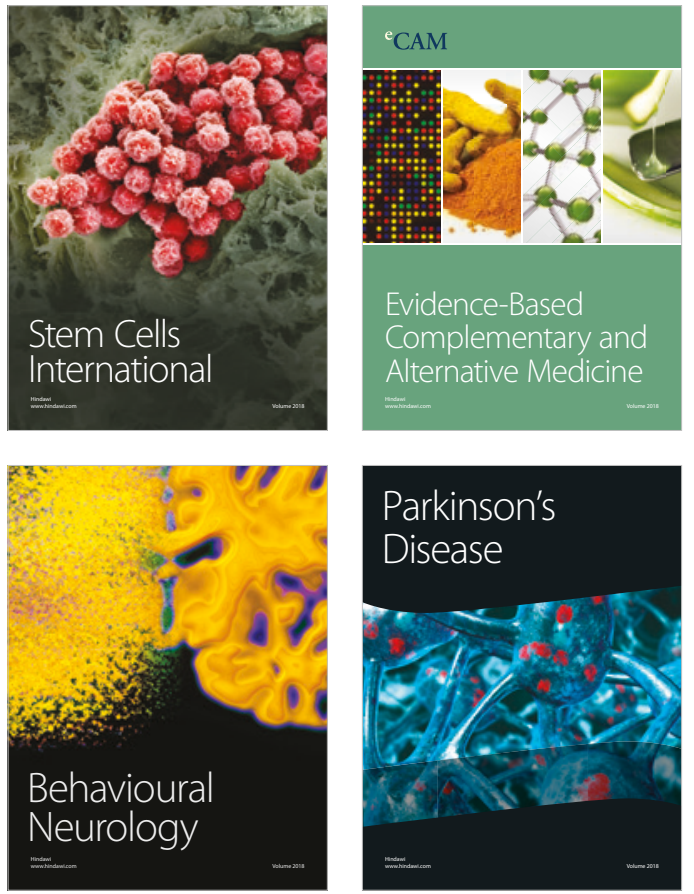

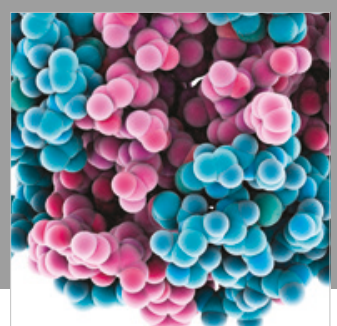

ournal of

Diabetes Research

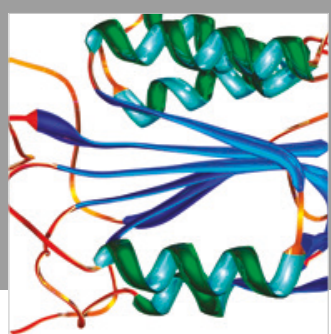

Disease Markers
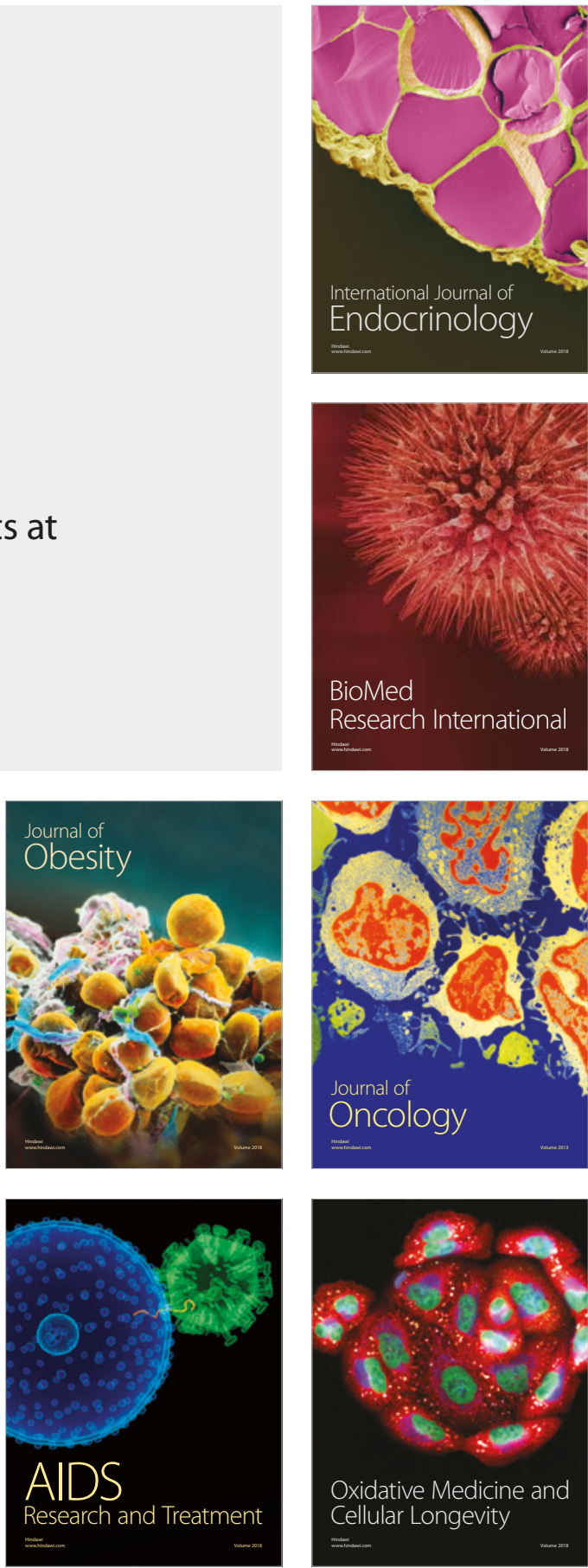